\title{
Interactive Interview: A Research Note
}

\section{Simeon Mitropolitski}

Key words: focus group; individual interview;

discursive dynamics; EU integration; postcommunism

\begin{abstract}
Forming focus groups as a particular technique for gathering information gives excellent results in tracing group discursive dynamics. Compared to individual interviews, however, it has an inherent setback. Expressing opinions without sufficient confidentiality protection makes informants hesitant. Trying to trace group dynamics at any cost may lead to losing important information regarding the research question. This research note proposes a new technique, interactive interviews, that combines the strengths of individual and group formats. In this technique, the researcher reproduces alternative discourses trying to engage informants in discursive dynamics identical to that found in focus groups. The results cover not only the eventual discursive change in informants, but also the discursive tensions that the researcher experiences. This note presents evidence of the testing of this technique on a case dealing with the role of EU integration on postcommunist democratization in Bulgaria.
\end{abstract}

\section{Table of Contents}

1. Introduction

2. Methodological Choices

3. Interactive Interview in Action

4. Conclusion

Acknowledgments

References

Author

Citation

\section{Introduction}

My research interest deals with the role of European integration in development of democratic political culture in post-communist countries that have become or aspire to become EU members. It is part of more general inquiries about the external impact on political system in the context of asymmetrical power relations. The main theoretical premise is that the dominant side in such relation does not impose automatically its will, but changes the way the subordinated side sees itself; this change in identity brings the possibility of behavioral changes that affect the functioning of the subordinated side's political system. This process is different from either an institutional learning or from strategic interests of both parties. [1]

The case study or real life context I use to develop the theoretical framework of my research question is the post-communist world of Eastern Europe. The countries that left communism in 1989 represent the subordinated side in the model; the dominant side is the European Union (EU); the asymmetrical power relation is inherent to the process of EU integration, in which the candidate countries must apply the EU conditionality in order to meet certain criteria for 
membership. Failing to do so may lead to unspecified delays of membership with high political consequences for the candidate countries' domestic political elites; succeeding to do so, on the other hand, may lead to grave social and economic consequences, again with consequences for the domestic political elites. Two post-communist countries in particular attract my attention, Bulgaria and Former Yugoslav Republic (F.Y.R.) of Macedonia. The former is a EU member since 2007; the latter, already with an official status of candidate, still waits to start the official negotiations for membership. [2]

I took the process of enlargement as an example of GRAMSCl's (1992 [1971]) asymmetrical power relation or cultural hegemony, in which the EU offers, but not imposes, candidate countries new identity. It combines national and transnational elements, some of which speed up and some of which slow down the process of democratization. Instead of making conclusions based only on the level of institutional transfer and acceptance of democratic procedures, using indices such as Freedom House or Polity IV Project, I look to the political culture on micro level, to the way people from different social layers understood this process and to the way this understanding affected their political life. [3]

In the following sections, first, I will present the main methodological choices and findings as a result of individual semi-structured interviews, and, second, I will introduce a new technique, interactive interview, which helps tracing group discursive dynamics without forming focus groups. [4]

\section{Methodological Choices}

My interviews as a main data collection technique ${ }^{1}$ occurred during three field trips to Bulgaria in June-July 2009, in June-August 2010 and in May-June 2011, and one field trip to the F.Y.R. of Macedonia in June-July 2010. In total, there were 84 semi-structured interviews in both countries (60 in Bulgaria and 24 in F.Y.R. of Macedonia). The qualitative interviews (WENGRAF, 2001) did not follow closed questionnaires; there were however some invariable topics, which were common to each subject, such as free associations and attitudes toward the European Union, or common within each country, such as the impact of the Schengen visa restrictions before 2001 for Bulgaria and before 2010 for the F.Y.R. of Macedonia ${ }^{2}$, or the constitutional name issue for the later ${ }^{3}$. Each interview took approximately one to two hours. Follow-up interviews in JuneAugust 2010, which were mostly face-to-face, with a few using Internet between the summer of 2009 and the summer of 2010 , took place with approximately a

1 To triangulate my findings I also used non-participatory ethnographic observations (e.g. SCHATZ, 2009) and text-analogy analyses (e.g. COLLEY, 2009).

2 Bulgarian citizens until 2001 and Macedonian citizens until 2010 had to apply for entry visa in order to travel to Schengen area, now comprising 26 European countries that have abolished passport and any other type of border control at their common borders.

3 Since the breakup of Yugoslavia in 1991, Greece fears that international recognition of Macedonia under its constitutional name may lead to territorial claims toward Greece. Therefore, Greece opposes the use of the name "Macedonia" without additional geographic qualifiers, e.g. "Northern" or "Upper." Until this issue is settled, Greece threatens to veto the adherence of Macedonia to international organizations, such as EU and NATO. 
third of the interviewees in Bulgaria. An additional set of interviews in Bulgaria in 2011 helped to discern internal dynamic of political discourses made possible as a result of EU influence. [5]

Forty Bulgarian informants were interviewed in June and July 2009 during the first field trip to Bulgaria. Approximately half of them plus the remaining Bulgarian informants were interviewed during the second field trip in the country in JuneAugust 2010. These follow-up interviews were generally shorter; they intended to confirm some main points of the interviewees, to clarify some uncertainties, and possibly to detect any substantial change in their views between 2009 and 2010 . Most Macedonian interviewees were met during the field trip in 2010. A few of them were first interviewed through the Internet in 2009 and in early 2010, with extensive follow-up face-to-face interviews in the republic taking place in the summer of 2010. [6]

Each interview was centered on the personality of the interviewee as a logically coherent and relatively independent cultural unit. It included biographic elements such as family history, formal education and general worldviews; the critical point in each interview was the subjective understanding of the moment of first "meetings" with European Union under all its forms, both material and symbolic. Whenever it was possible, the informants were given the opportunity to comment on the biographical counterfactuals without any limitations: "what if there was no ...," followed by the key moment of each personal experience involving European Union, such as the first trip to Europe, first foreign scholarship, first foreign employer, or first EU accession membership talks. [7]

A special attention was given to the capacity of each interviewee to build upon the "European" topics on his or her own, to provide his or her own examples and personal experience, once the general line of conversation was set up. Overall, every informant had the liberty to wrap up the "European" topic(s) within his or her own personal agenda, to put them among the other personal priorities, and in some cases, to refuse altogether to embark on such "European" journey; in the latter case the interview had to focus on the personal reasons for this refusal. The locations of the interviews were meant to accommodate the informants emotionally as much as possible. Generally, the interviewees themselves decided where and when to meet me (at home, at work [in the office or at the lobby]), in a park, in a cafeteria. At the start of each interview I repeated where my research interests lied; my research goals were clearly stated when the interviews were originally set up. I reiterated that the interviewees were in full control over the interview duration and I assured them that their identity under all circumstances would remain confidential. [8]

Regarding the choice of informants the main strategy in both countries was to find governmental officials, private companies', non-governmental organizations', media and university staff who were supposed, by the nature of their jobs, to have some firsthand personal knowledge of the European Union and its overall influence in their respective country. Once the initial contacts were established, 
these informants provided additional contacts to enlarge the number of interviewees in an effect of snowballing (GOODMAN, 1961). [9]

As far as the general population was concerned, I followed three separate avenues in order to select potential interviewees. First, I contacted friends and former colleagues (schoolmates, journalists, NGO officials); second, I met with newspaper readers from the Internet newspaper discussion clubs who looked interested to discuss the issues I was interested in; third, I used casual meetings with previously unknown persons during my trips within Bulgaria and between Bulgaria and Macedonia. The preference within the group of state civil servants, current and former, NGO officials and media and university staff was to meet those with extensive links and knowledge of the EU matters. The opposite criterion applied while choosing among the ordinary people; the goal was to see how far EU influence, if any, could be traced among those whose lives did not require any particular knowledge or personal business relations with the EU. [10]

The spoken language that I used in all interviews except three (with the European Union representatives in Skopje where the languages were French and English) was Bulgarian. The Bulgarian and the Macedonian informants spoke Bulgarian and Macedonian respectively. All Macedonian interviewees felt comfortable with such an arrangement; none of them demanded shifting to a "neutral" third language, such as English or French, although such a possibility was clearly stated at the beginning of each interview, nor did they demand services of a Bulgarian-Macedonian translator. [11]

As far as the results of individual interviews were concerned, I collected valuable information regarding different trajectories of political culture development. Different elements of EU integration, such as new rules, new freedom of movement, the asymmetrical power relation with the EU, to mention just a few, made informants politically more or less active, by either increasing or decreasing the significance of the act of voting, by contributing to their willingness to conceive acts of political collective action, and by increasing or decreasing their subjective sense of competence on sensitive political issues. As a result of EU integration I found three main political culture trajectories in Bulgaria and two in Macedonia. First, in Bulgaria, some people became more politically active within the national political system; second, some people became more active on a European level and less active on a national level; and third, some people became politically less active. In Macedonia, some of the informants accepted the asymmetrical power relationship with Brussels and were ready to make all necessary concessions to successfully join the EU while others asserted their national identity and rejected power asymmetry with the EU (see for details MITROPOLITSKI, 2013, 2014). [12] 


\section{Interactive Interview in Action}

People reported the influence of EU integration on their thinking and behavior as they saw it. They could not, however, report the relative influence of their own understanding in comparison with the other possible trajectories, some of which they were unfamiliar with and some of which they strongly rejected or felt indifferent to. They were culturally very present within their respective subcultures where their trajectories look like the most, if not the only logical consequences of their particular circumstances. This research put each trajectory within the larger context of other trajectories, each opinion within the sea of interacting opinions. The goal was not to show which one was numerically more present within society. Quantitative methods, which are not part of this research, would be more powerful in answering this type of question. I would like to present some results that show, in real life interaction, which trajectories appear to be becoming dominant and which ones are marginalized or transformed. [13]

One way of collecting data, using qualitative methods, would be to organize focus groups (BLOOR, FRANKLAND, THOMAS \& ROBSON, 2001; WUTICH, LANT, WHITE, LARSON \& GARTIN, 2010). Each group would include participants who have originally fallen in different cultural trajectories. The discussion would show which opinion becomes dominant, and which one is subordinated or marginalized or transformed. For the purpose of this research, it would not have been appropriate to organize a textbook version of focus groups, a technique particularly suited for understanding discursive group dynamics (LINDLOF \& TAYLOR, 2002). If people who confidentially gave their opinions were made to defend these opinions against other informants I would break the promise of confidentiality that was given toward each individual participant. If new people were contacted to form focus groups, that would extend the time of gathering information without necessarily producing any additional information. Another major disadvantage of this technique, the focus group, would have been its inherent artificiality; people may change or modify their opinions simply because they do not feel comfortable outside their usual social habitat. The individual interviews were conducted taking into account the specific wishes of each participant regarding the time and the place. It would have been impossible to accommodate all participants within a focus group by finding equally suitable place and time, which, finally, would have given unfair preference to some of them. [14]

To solve this methodological problem, I used two other tools that I found appropriate for this particular research. First, I used my ethnographic notebook that collected non-participant observations in both Bulgaria and Macedonia. Second, I used information that was gathered through a new set of individual interviews with some of the previous interviewees; these meetings sought intentionally to provoke reactions as if interviewees and myself were a focus group that reproduced the dynamics of different discourses. In other words, I confronted my interlocutors with arguments that I knew would be considered as opposed to theirs. [15] 
Two events during my field trips to Bulgaria and Macedonia gave me the hint to use this quasi focus group technique. The first occurred on my bus drive between the two capital cities, Sofia and Skopje in 2010. The bus of 50 seats was almost empty; only 10-15 passengers were present, almost all Bulgarians. At the Macedonian border and customs control some of the passengers became nervous because about the long time of waiting that was not warranted for any obvious reason. They started to discuss whether such waiting, all other things being equal, could have occurred in Germany. The passengers divided into two camps. The first argued that German border and customs officers were simple bureaucrats that followed written instructions; the second, on the contrary, argued that all frontier and customs officers around the world were equally corrupt, that all they wanted was to find paper irregularities or illegal merchandise in order to take personal profit out of it. The waiting time was long and discussion went further and further, each side provided new arguments, personal experiences, and gossip. The discussion ended when all those, except one, who defended that German officers would not be as corrupt as their Macedonian and Bulgarian colleagues accepted the opposite view. The interaction confirmed which discourse was dominant, that all officers around the world were corrupt. The only person who kept his minority position decided to abandon discussion without however accepting his opponents' arguments. This was a good example of a focus group without moderator; two positions were clearly identified before coming into clash; arguments were provided for each one of them; the interactive dynamic produced a dominant discourse. [16]

The second event took place a week later, in Skopje. I met at a lunch table with four persons, political cartoonists, whom I had individually met before. They did not fall into the group of Macedonian informants. The reason I met them was to seek their comments on some of their political cartoons, which were with or without any link to my research project. These people knew each other well and knew the reason of my staying in Macedonia. They also knew that I had spoken in private with each one of them. What they did not know was what the others had told me during their private meetings. The common meeting was planned as a friendly chat, outside my research, but in the Balkans a friendly chat has two necessary requisites: a cup of coffee and a discussion on the domestic and international political situation. During this lunch, as a foreigner, I had a good excuse not to get too involved in Macedonian domestic political topics. My four hosts, on the contrary, without being asked, used the chance to present again their general political views. I already knew that two of them were close to the center-right nationalist government and that the other two were close to the center-left ex-communist opposition. Again, as in the bus, their views collided on a whole spectrum of issues, beginning with the rights of Albanians to put their flags on public display to the prospects of changing the name of the republic. The center-right cartoonists quickly monopolized the nationalist card and their opponents found it harder and harder to put up new arguments against their colleagues. As in the bus, as an outside observer, I saw how one discourse became dominant; the euro-skeptics won against the euro-optimists. This victory, as in the bus, had nothing to do with numerical superiority of its supporters; they simply put their opponents on the defensive and occupied the symbolic center of 
social normality. Pending new arguments from the dissidents that could convince everybody and produce a new dominant discourse, the old dominant discourse remained dominant. [17]

These two events made me browse my notebooks for other similar exchanges of opinions in both countries, directly observed on the streets or on the radio and TV talk shows. I found that in Bulgaria, several spontaneous discussions had occurred between people who defended two extreme positions on the issue of whether it was worth voting within a political system where the vote could change the government but not the policies. The results were that those who advocated political apathy always took over by silencing those who advocated pro-active social and political positions. The victory of this a-political position was even more conspicuous if I put on the balance the fact that this position ran against the official state discourse of encouraging political participation. The key mechanism that explained this victory was the shaming of the opponents. Optimistic political discourse disappeared when it was confronted with facts or rumors of international conspiracies and the universal nature of state corruption that made people powerless and defenseless. My observations in Bulgaria showed that people who publicly advocated a-political behavior in Bulgaria seemed to have the wind in their sails; the reason why some people could still behave as political beings in Bulgaria was probably due to the fact that they lived in relative cultural isolation from other discourses that advocated a-political behavior. In Macedonia the picture was quite different. Spontaneously developing political discussions among people who initially defended a-political and participatory positions ended up exclusively in favor of those with pro-active political and social positions. The mechanism, ironically, was the same, shaming the opponent; this time the shame came from the inability of some Macedonians to be ready to take their share of the common national burden. Appearing treacherous in Macedonia in the eyes of friends and family was equally unacceptable as appearing politically naïve and subservient in Bulgaria. [18]

These observations made me plan a third field trip to Bulgaria in 2011, which had to clarify the question of the internal discursive dynamic. As I had to keep the confidentiality of my informants, the quasi focus groups that I organized were in fact interviews where I had to defend positions opposed to those of my interviewees. Instead of using the format of ethnographic interviews where the interviewer guides through the topics but tries not to confront the interviewee, this time I had to increase the emotional temperature by risking that the informant might cut the interview short. [19]

By observing that shaming was one of the key mechanisms of exchange between discourses, I had to use it myself abundantly. For example, those who defended EU integration as a civilizing project had to be called "naïve" and "indoctrinated," those who withdrew from politics or planned to leave country had to be called "traitors" and "fugitives." These were my initial plans. In fact, once I faced my "opponents" I did not have the courage to be as aggressive as I planned. My informants had opened their hearts and minds to me and I could not cross a line that would make me appear as ungrateful in their eyes. So instead of attacking 
them personally, I attacked their positions using information that I could easily bring from other sources. Instead of saying "You are so naïve, on the contrary, I think that ...," I simply said: "But how about an opinion that obviously contradicts yours," and then cite an opinion, which represented my informant as "naïve." My interlocutors felt the heat, but did not consider it as a personal attack coming from me. To save face, they had to find arguments, if not to defend their opinions then at least to keep up the conversation. In this way I interviewed seven persons from the pool of my previous informants; four of them, "Plamen"4, "Rumi"5, "Tosho"6 and "Anette"7, were initially classified as people who had become or had remained a-political despite or because of the symbolic presence of EU integration; the other three informants, "Kamen"8, "Cyril"9 and "Mira"10, were people who were classified as politically more active, more competent and ready to contemplate new forms of collective action because of EU integration. In these interviews, after a brief introductory section in which I double-checked that they were still standing by their previous positions, I introduced the alternative views and listened to their reactions. [20]

The first group of informants, the a-political people, comfortably held firm their previous positions despite the presence of an alternative pro-active political discourse that I tried to maintain to the best of my abilities. Their common points were that criminals ruled Bulgaria and that taking active part in such a system was shameful. They also pointed out the fact that as a Bulgarian living abroad for many years I had lost touch with Bulgarian reality, a reality which was much worse than the one that appeared to foreign tourists. "Plamen" several times said during the meeting "the things are different [translation: worse] from what people say and they get worse with each day passing ... there is no point to try to change them."11 "Rumi" said: "you in Canada live so well that you cannot understand how we struggle here ... we are so desperate that nothing can change for better." "Tosho" immediately embarked on international conspiracy theses: "I know well that all these rosy fairy tales are fabricated abroad and aim to destroy the Bulgarian nation." "Anette" built her line of defense by repeating the phrase: "Can't you see yourself how bad things are here." Instead of being shamed for their lack of enthusiasm, this group of people tried in turn to shame me for being too enthusiastic, for even listening to enthusiastic discourses. As an instrument of shaming they used the obvious fact that I had been living abroad for many years and therefore could not have objective understanding of the situation in my native country. None of them seemed to contemplate any change in his or her position. [21]

442 years old, male, private company (restoration)

539 years old, female, painter

640 years old, male, police officer

736 years old, female, school teacher

841 years old, male, state civil servant

935 years old, male, state civil servant

1030 years old, female, NGO (former state civil servant)

11 These and the following quotes of Bulgarian informants I translated into English. 
The informants of the second group, in which two people were currently civil servants and one a NGO employee and a former civil servant, were seemingly more nervous to defend their positions facing open opposition. They, however, never used in defense the fact that I was living abroad to discredit the alternative discourse that I was maintaining. They also never tried to defend their positions by pointing out that facts were "clear enough" and "spoke for themselves." To the contrary, they tried to present their positions as too complicated to be part of a public discussion. They usually made a clear distinction between themselves and ordinary people. According to "Cyril," "Bulgarians are misinformed and therefore cannot make good judgment on EU integration and on all the good things that come along with it." "Kamen" took a condescending view on his compatriots: "It is irrelevant what people say, because at the end they will obey new laws as always." "Mira" was less optimistic on this point; therefore she suggested: "We need a new totalitarian state; people need a strict master whom they should fear, not endless discussions." Unlike the first group of informants who associated themselves with civil society, with the normal ordinary people, the second group looked at themselves as being above society and above doubts regarding the future course of social development. "Cyril" never thought as a Bulgarian he could be misinformed; "Kamen" never thought that what he was thinking was irrelevant; "Mira" never thought that she would be subjected to the same totalitarian state as the ordinary people. Their views were not supposed to be put to democratic discussion. "Cyril" complained that "people talk too much, but we need to work"; "Mira," in harmony with her totalitarian dreams, added that "[w]e seem to have too much democracy and too little order." To sum up, this second group of informants, when felt endangered, challenged the right of their opponents to have independent opinions. Contrary to PRIDHAM's pro-democratic expectations (2005), these informants did not use their EU democratic know-how in order to replicate it in their domestic actions. EU integration made them politically more active, but they were ready, when they felt in danger, to negate the democratic rights of their fellow citizens. In agreement with RAIK (2004) and BIDELEUX (2001), these informants, as former and current members of the extended political executive, used EU integration to detach themselves symbolically from the local society and its specific interests. They could maintain their specific views as long as the state they were so deeply identifying with remained relatively autonomous from society. [22]

\section{Conclusion}

Interactive interview, in which the focus switches from the informants to their interaction with the researcher, is a useful tool for solving the dilemma of confidentiality as far as group interviews are concerned. It also paves the way for offering a new set of techniques that better suit constructivist types of research. Further research is necessary to explore the usefulness of this new technique, compared to other techniques. It will be premature to proclaim the end of focus groups as an independent technique for gathering information. Interactive interviews are proven to be a useful substitute when it comes to reproducing dynamics of interaction of two different opinions regarding one particular stimulus. It is not clear whether interactive interviews with only one 
researcher/moderator can successfully reproduce more complicated dynamics of more than two different opinions. [23]

This new format does not add ethical worries to the methodological protocol. It was the need to guarantee confidentiality that has initially triggered this new technique that provided answers regarding group discursive dynamic without revealing informants' identity. Their anonymity was maintained by using fake names while coding and reporting the findings. The informants had given their consent to take part in this research and were free to abandon it at will without providing any justification at any time. Although no semi-directed interview setting can create a stress-free environment for the informants, I did try to maintain the interactions within reasonable emotional borders, a role that in a normal focus group setting is played by the moderator (CAMPBELL \& STANLEY, 1966). [24]

\section{Acknowledgments}

I want to thank the Social Sciences and Humanities Research Council of Canada (SSHRC) for funding my doctoral research, which produced reflections on issues of qualitative methodology included in this article. I also want to thank Russell BERNARD, Norman DENZIN, Paul ATKINSON, Ronald CHENAIL for reading earlier versions of the manuscript and for their valuable suggestions.

\section{References}

Bideleux, Robert (2001). "Europeanisation" and the limits to democratization in East-Central Europe. In Geoffrey Pridham \& Attila Agh (Eds.) Prospects for democratic consolidation in EastCentral Europe (pp.25-54). Manchester: Manchester University Press.

Bloor, Michael; Frankland, Jane; Thomas, Michelle \& Robson, Kate (2001). Focus groups in social research. Thousand Oaks, CA: Sage.

Campbell, Donald \& Stanley, Julian (1966). Experimental and quasi-experimental designs for research. Chicago, IL: Rand McNally.

Colley, Linda (2009). Britons: Forging the nation 1707-1837. New Haven, CT: Yale University Press.

Goodman, Leo (1961). Snowball sampling. Annals of Mathematical Statistics, 32(1), 148-170.

Gramsci, Antonio (1992 [1971]). Prison notebooks. New York: Columbia University Press.

Lindlof, Thomas \& Taylor, Bryan (2002). Qualitative communication research methods (2nd ed.). Thousand Oaks, CA: Sage.

Mitropolitski, Simeon (2013). The role of European Union integration in post-communist democratization in Bulgaria and Macedonia. Canadian Slavonic Papers, 55(3-4), 365-389.

Mitropolitski, Simeon (2014). EU integration, enforcement of and impediment to national identity in Bulgaria and Macedonia. Region: Regional Studies of Russia, Eastern Europe and Central Asia, 3(2), 309-326.

Pridham, Geoffrey (2005). Designing democracy: EU enlargement and regime change in postcommunist Europe. London: Palgrave Macmillan.

Raik, Kristi (2004). EU accession of Central and Eastern European countries: Democracy and integration as conflicting logics. East-European Politics and Societies, 18(4), 567-594.

Schatz, Edward (Ed.) (2009). Political ethnography: What immersion contributes to the study of power. Chicago, IL: University of Chicago Press. 
Wengraf, Tom (2001). Qualitative research interviewing. London: Sage.

Wutich, Amber; Lant, Timothy; White, Dave; Larson, Kelli \& Gartin, Meredith (2010). Comparing focus group and individual responses on sensitive topics. Field Methods, 22(1), 88-110.

\section{Author}

Simeon MITROPOLITSKI is a part-time professor of political science and methodology at University of Ottawa and University of Montreal. His research and publications focus on the area of postcommunist studies, comparative democratization, political culture and qualitative methods of analysis.

Contact:

Simeon Mitropolitski

University of Ottawa

414-5526 Ashdale

Cote Saint Luc, Quebec, Canada, H4W2B7

Tel.: 1-514-484-8167

E-mail: smitropo@uottawa.ca

URL:

https://independent.academia.edu/SimeonMitro politski

\section{Citation}

Mitropolitski, Simeon (2015). Interactive Interview: A Research Note [24 paragraphs]. Forum Qualitative Sozialforschung / Forum: Qualitative Social Research, 16(1), Art. 8, http://nbn-resolving.de/urn:nbn:de:0114-fqs150189. 